\title{
SENTIMENTOS DE MULHERES SOROPOSITIVAS ACERCA DA NÃO AMAMENTAÇÃO
}

\section{FEELINGS OF SEROPOSITIVE WOMEN TOWARDS NON-BREASTFEEDING}

\section{SENTIMIENTOS DE MUJERES SEROPOSITIVAS SOBRE EL NO AMAMANTAMIENTO}

\author{
Marizete Argolo Teixeira ${ }^{1}$ \\ Mirian Santos Paiva ${ }^{2}$ \\ Pablo Luiz Santos Couto ${ }^{3}$ \\ Jeane Freitas Oliveira ${ }^{2}$ \\ Rafael Moura Coelho Pecly Wolter ${ }^{4}$
}

\begin{abstract}
Como citar este artigo: Teixeira MA, Paiva MS, Couto PLS, Oliveira JF, Wolter RMCP. Sentimentos de mulheres soropositivas acerca da não amamentação. Rev baiana enferm 2017;31(3):e21870.

Objetivo: conhecer os sentimentos de mulheres soropositivas para o HIV e HTLV sobre a não amamentação. Método: pesquisa qualitativa, fundamentada na Teoria das Representações Sociais, realizada com 134 mulheres atendidas em Centros de Referências para IST/aids e HTLV, na cidade de Salvador, Bahia, Brasil. Para produção das informações foram utilizadas o survey descritivo e a dinâmica interativa. Foi utilizada a análise de conteúdo temática. Resultados: as entrevistadas revelaram sentimentos de tristeza, medo, raiva, culpa e incerteza diante da decisão de não amamentação. Essa decisão esteve ancorada no desejo de evitar a contaminação do seu filho para o vírus da imunodeficiência adquirida e/ou para o vírus T-linfotrópico humano. Conclusão: os sentimentos das entrevistadas acerca da não amamentação estão permeados por conflitos oriundos de padrões socioculturalmente estabelecidos com relação à amamentação. Na prática profissional, enfermeiras têm a possibilidade de intervir na situação da não amamentação apoiando a mulher na sua decisão.
\end{abstract}

Descritores: Saúde materno-infantil. Amamentação. Enfermagem. HIV. HTLV.

Objective: to know the feelings of HIV-and HTLV-positive women towards non-breastfeeding. MethodObjective: to know the feelings of HIV-and HTLV-positive women towards non-breastfeeding. Method: qualitative research based on the Theory of Social Representations, carried out with 134 women assisted at IST/AIDS and HTLV Reference Centers, in the city of Salvador, Babia, Brazil. A descriptive survey and interactive dynamics were used to produce the information. Data were examined through thematic content analysis. Results: the interviewees revealed feelings of sadness, fear, anger, guilt, and uncertainty regarding the decision of not to breastfeed. This decision was anchored in the intent to protect the child from being contaminated with the acquired immunodeficiency virus and/or human T-lymphotropic virus. Conclusion: the feelings of the interviewees towards non-breastfeeding are permeated by conflicts arising from socio-culturally established patterns regarding breastfeeding. In professional practice, nurses have the possibility to intervene in the situation of non-breastfeeding by supporting the women in their decision.

Descriptors: Maternal and child health. Breastfeeding. Nursing. HIV. HTLV.

\footnotetext{
Enfermeira. Doutora. Professora Titular do Departamento de Saúde ll da Universidade Estadual do Sudoeste da Bahia. Jequié, Bahia, Brasil. marizeteargolo@uesb.edu.br Enfermeiras. Doutoras. Professoras Associadas do Departamento de Enfermagem da Universidade Federal da Bahia. Salvador, Bahia, Brasil.

Enfermeiro. Mestre. Professor do Colegiado de Enfermagem da Faculdade Guanambi. Guanambi, Bahia, Brasil.

Psicólogo. Doutor. Professor do Programa de Pós-graduação em Psicologia Social da Universidade do Estado do Rio de Janeiro. Rio de Janeiro, RJ, Brasil.
} 
Objetivo: conocer los sentimientos de mujeres seropositivas para el VIH y el HTLV, sobre el no amamantamiento. Método: investigación cualitativa, basada en la Teoría de las Representaciones Sociales, realizada con 134 mujeres atendidas en Centros de Referencias para el IST/sida y HTLV, en la ciudad de Salvador, Bahia, Brasil. Para la recolección de datos se utilizó el survey descriptivo y la dinámica interactiva, además del análisis de contenido temático. Resultados: las entrevistadas revelaron sentimientos de tristeza, miedo, rabia, culpa e inseguridad delante de la decisión de no amamantar. Esa decisión se basó en el deseo de evitar la contaminación de su hijo con el virus de la inmunodeficiencia adquirida y/o para el virus T-linfotrópico bumano. Conclusión: los sentimientos de las entrevistadas sobre el no amamantamiento, están permeados por conflictos oriundos de patrones establecidos socioculturalmente con relación al amamantamiento. En la práctica profesional, las enfermeras tienen la posibilidad de intervenir en la situación del no amamantamiento apoyando a la mujer en su decisión.

Descriptores: Salud materno-infantil. Amamantamiento. Enfermeria. VIH. HTLV.

\section{Introdução}

A soropositividade para o vírus da imunodeficiência adquirida (HIV) e o vírus T-linfotrópico humano (HTLV) contraindica a amamentação, pelo risco adicional da transmissão vertical ${ }^{(1-2)}$. Salienta-se que a transmissão vertical do vírus por lactação é importante fator de risco, seja pelos fatores biológicos já conhecidos, seja pelos sociais $^{(3-4)}$. Diante do impasse que é romper com questões sociais, culturais e emocionais que implica na dificuldade de mulheres que estão impedidas de amamentar para manter o bebê sadio, surge um desafio para as áreas do conhecimento, especialmente a da saúde ${ }^{(1,5)}$.

Em decorrência da contaminação por vírus e do risco de transmissão vertical pelo leite materno, é fundamental que a amamentação deixe de ser vista apenas como fonte de vida e saúde, compreendendo-a também como fonte de doença e morte. Diante da infecção pelo HIV ou HTLV, a suspensão da amamentação é necessária, pois, mesmo com o leite materno apresentando inúmeras vantagens, como anticorpos, células nucleares e outros fatores de proteção aos recém-nascidos, a presença desses vírus torna o leite-humano infectado(5).

O HIV é o responsável pelo desenvolvimento da síndrome da imunodeficiência adquirida (aids) em seres humanos ${ }^{(4)}$ e o HTLV I pode levar as pessoas a desenvolverem doenças, como a leucemia/linfoma de células T do adulto (ATL) e a mielopatia/paraparesia espástica tropical associada ao HTLV-I (HAM/TSP). Por sua vez, o HTLV II é causador de doenças neurológicas similares a HAM/TSP e leucemia de linfócitos granulares, tendo sido também isolado ou detectado em pacientes com leucemia linfocítica crônica com neutropenia, leucemia prolinfocítica, linfoma cutâneo, síndrome de Sézary, dermatite esfoliativa, síndrome da fadiga crônica e distúrbios neuro degenerativos súbitos ${ }^{(3,6-7)}$.

Desse modo, com o advento das infecções pelo HIV e HTLV, promover, proteger e apoiar a amamentação passa a ter novo significado, no qual não se pode pensar somente na transmissão vertical, mas, sobretudo, na subjetividade das mulheres soropositivas. É um momento em que se faz necessária a construção-desconstrução-reconstrução de significados e representações, não somente por parte das mulheres que deixarão de amamentar, como também por parte dos profissionais de saúde que têm na assistência o auxílio ao enfrentamento dessas mulheres na vivência da soropositividade e da não amamentação.

Assim, surgiu como questão norteadora: Quais os sentimentos expressos nas representações sociais de mulheres sobre a não amamentação? Visando responder este questionamento, formulou-se o objetivo: conhecer os sentimentos de mulheres soropositivas para HIV e HTLV sobre a não amamentação.

\section{Método}

Trata-se de uma pesquisa qualitativa norteada pela Teoria das Representações Sociais, desenvolvida com 134 mulheres soropositivas para o 
HIV ou para o HTLV atendidas, respectivamente, em um Centro de Referência Estadual para IST/ aids e um Centro de Referência para HTLV, localizados no município de Salvador, Bahia, Brasil. Os dados apresentados constituem recorte de uma pesquisa maior financiada pelo CNPq.

A participação das mulheres deu-se mediante convite feito diretamente a cada uma, na sala de espera das unidades, enquanto aguardavam consulta para si e/ou para seus filhos, em dias e horários diversos, no período de agosto de 2008 e abril de 2009. Foram adotados como critérios de inclusão: ser cadastrada na unidade, o que implicava que tinha diagnóstico de soropositividade para o HIV ou HTLV, ter idade acima de 18 anos e ter engravidado alguma vez na vida.

O número de participantes foi limitado, uma vez que foi tomado como parâmetro a quantidade de mulheres positivas para o HTLV, dado que, entre os grupos participantes, era o universo menos conhecido. Assim, buscou-se fazer equivalência com as soropositivas para o HIV. Desse modo, optou-se por excluir aquelas que não frequentavam periodicamente os Centros de Referência.

Do total das participantes, 70 eram soropositivas para o HIV (SP HIV) e 64 soropositivas para o HTLV (SP HTLV). A idade das mulheres (SP HIV) variou entre 18 a 54 anos; por sua vez, as mulheres (SP HTLV) oscilou entre 22 a 86 anos. De modo geral, entre todas as participantes, a maioria cursou o Ensino Fundamental Incompleto, estava desempregada, autodeclarou-se de cor preta e afirmou conviver em união consensual.

Para este artigo foram consideradas as informações apreendidas pelas técnicas do survey descritivo, contendo questões referentes ao conhecimento sobre o HIV/aids, HTLV, sentimentos sobre a soropositividade e não amamentação, atitudes e comportamentos diante da não amamentação. Nesse momento, as participantes foram expostas a uma situação hipotética por meio de uma Dinâmica Interativa (DI), criada especialmente para este estudo, e puderam emitir suas opiniões e expressar seus sentimentos sobre o objeto estudado.
As informações obtidas com as questões abertas relativas ao survey e à DI foram analisadas por meio da análise de conteúdo temática. Os depoimentos foram analisados tomando por base as unidades de registros correspondentes a cada questão e delas extraíram-se as palavras e frases-tema que formaram as categorias temáticas pela sua ocorrência e co-ocorrência. Da transversalização dos dados, isto é, das informações que se atraíram por similaridade e/ou se complementaram, emergiram três categorias, que serão apresentadas e discutidas a seguir.

As mulheres tiveram suas falas identificadas com o número arábico referente à ordem em que ocorreu a entrevista, seguido pela sigla referente à sua condição de soropositivadade, seja para HIV ou HTLV (exemplo: Mulher 22 SP HIV ou Mulher 33 SP HTLV).

O desenvolvimento do estudo atendeu às normas nacionais e internacionais de ética em pesquisa envolvendo seres humanos.

\section{Resultados}

Após a análise de conteúdo das falas das participantes da pesquisa, foi possível conhecer as representações sociais reveladas e expressas nos sentimentos, sendo possível chegar aos temas e, consequentemente, às três categorias: "Entre o desejo de amamentar e o desejo de manter a vida"; "O que eu vejo no meu corpo: sentimentos acerca das alterações físico-orgânicas diante da não amamentação"; "A obscuridade diante da janela da vida: desafio do preconceito social".

Essas categorias permitiram compreender que as representações construídas socialmente pelas informantes sobre o HIV e HTLV influenciaram sua decisão de não amamentar devido ao contágio do seu leite materno, mesmo que a amamentação tenha sido construída como uma forma de afirmação da maternidade. Esta decisão foi objetivada por meio das lágrimas que rolaram sobre seus rostos, permitindo-lhes exteriorizar o sentimento de tristeza, angústia, culpa, medo e raiva, quando seus filhos choravam e elas não podiam alimentá-los com o leite que fluía de suas mamas, pois estava contaminado por vírus. 


\section{Entre o desejo de amamentar e o desejo de manter a vida}

De acordo com relato das participantes, a não amamentação constituiu-se num conflito entre o desejo de amamentar e o desejo de manter a saúde de seus filhos(as) gerado pela condição de soropositividade para o HIV ou para o HTLV. O amamentar foi um sonho não realizado, uma vontade reprimida e um querer sufocado devido a sua soropositividade. Tal fato pode ser explicado pelas representações que elas atribuem à amamentação como mais importante que o parto e um momento de felicidade.

[...] as mães têm vontade de dar peito à criança, mas a gente não pode dar. (Mulher 24 SP HIV).

Eu senti [...] não poder amamentar [...] era um sonbo que tinha de amamentar, mas, naquele caso, eu tinha que me conformar de não passar a doença para minha filha. (Mulher 17 SP HIV).

É complicado [...] eu acho que o contato na amamentação é ainda mais importante que o parto. (Mulher 21 SP HTLV).

O conflito aumentava quando os filhos choravam e elas sentiam o peito transbordando de leite que não iria ser utilizado, por estar carregando um vírus considerado mortal, especialmente quando não tinham à sua disposição o leite artificial para ser oferecido.

[...] quando eu olhava para o meu peito [...] vendo aquele leite, eu querendo amamentar, sem poder dar a ele, chegava a ficar desesperada, tinha hora que eu chorava. (Mulher 33 SP HIV).

[...] tinha vez que eu queria tirar para dar mama a ele [...] teve uma vez mesmo que o leite que ele tomava não veio, ficou duas vezes sem vir, eu fique doida e ele com fome [...] eu disse: eu vou tirar [...] e vou dar mama ao meu filho. Ai uma colega minha [...] falou: não faça isso não, que você sabe que ele corre todo risco do mundo se você dá mama [...] (Mulher 32 SP HIV).

Durante a aplicação da técnica da DI, as mulheres evidenciaram sentimentos de tristeza, medo, culpa, incerteza, frustação e raiva pela impossibilidade de amamentar.

Quando não amamentei, fiquei muito triste [...] (Mulher 3 SP HIV).

[...] fiquei triste [...] eu queria que minha filha tivesse amamentando. (Mulher 28 SP HTLV).

[...] eu fiquei tão triste! [...] porque o que eu queria era dar mama. (Mulher 32 SP HTLV).
Quando eu não amamentei meu filbo eu sofri demais [...] eu vendo ter leite e não poder dar aos meus meninos [...] eu fiquei muito abalada. (Mulher 9 SP HIV).

[...] não amamentar é uma frustração. A gente sabe que, no fundo, fica faltando um pedacinbo. (Mulher 8 SP HIV).

\section{O que eu vejo no meu corpo: sentimentos} acerca das alterações físico-orgânicas diante da não amamentação

De acordo com as entrevistadas, as alterações físico-orgânicas presentes em seus próprios corpos objetivavam a condição de puerpério. Contudo salientavam diariamente o sentimento de tristeza, sofrimento e dor pela impossibilidade de não amamentação.

Lá na maternidade, quando acabei de ter o nenê, eles me deram uma injeção que é pra secar o leite, mas não seca logo. Eu criei os seios que ficaram mesmo gigantes. Eu tive febre, foi horrivel [...] até ele secar [...] foi muito doloroso mesmo. (Mulher 9 SP HIV).

Além de ter recebido a medicação para suprimir a lactação na maternidade, outras medidas para aliviar os desconfortos mamários foram utilizadas pelas entrevistadas, na tentativa de inibir a produção. Entretanto, essas medidas também causavam dor física e psicológica.

Para secar o leite [...] eu fiquei tirando o leite, toda manhã fazia a compressa morna [...] e também recebi medicação, mas não secou, veio secar em casa. Lá na maternidade, mandou fazer a compressa de gelo para não endurecere continuasse retirando o leite. (Mulher 3 SP HIV).

[...] fica inchado, você não aguenta, tem febre, eu tive febre e frio [...] ai meu marido comprou [um oleozinho], eu passei fui pegando o pente, doendo muito [...] saindo, pingava, pingava [...] fiquei três dias e aí que secou de vez. (Mulher 5 SP HIV).

Foi uma tristeza imensa quando enfaixou meu peito [...] uma dor imensa. Eu não queria nem deixar! (Mulher 32 SP HIV).

Para as entrevistadas, ser mãe é um destino natural da mulher, sendo normal e natural uma mulher amamentar seu(sua) filho(a), especialmente se ela é saudável, conforme demonstrado no discurso a seguir:

[...] para mim isso é normal, é natural porque toda crianca tem que mamar [...] a mãe estando saudável é importante dar o leite. (Mulher 29 SP HIV). 
Assim, o reconhecimento de que é normal a mulher amamentar e os benefícios do leite materno para a saúde da criança motivou algumas mulheres a optarem pela amamentação, mesmo conhecendo o seu estado sorológico. Desta forma, o desejo de amamentar sobrepõe-se aos riscos que o leite contaminado pode causar ao organismo infantil, conforme ilustram os discursos a seguir:

[...] para mim isso é normal, é natural porque toda criança tem que mamar [...] (Mulher 29 SP HIV).

Eu mesma conbeço uma [mãe] que pegou o vírus do $H I V$, engravidou [...] as crianças nasceram sem o vírus [...] mas ela amamentou as crianças mesmo sabendo [da soropositividade] [...] então ela sabia, mas nem por isso ela disse que não ia amamentar. Ela amamentou eles até grande [...] não sei se as crianças pegaram ou não o vírus. (Mulher 15 SP HIV).

\section{Obscuridade diante da janela da vida:} desafio do preconceito social

O não amamentar devido à soropositividade obrigou as mulheres a criarem situações para justificar socialmente a não amamentação, para não sofrerem o preconceito e a discriminação de serem soropositivas. Sobretudo, por falta de coragem de revelar aos familiares e/ou pessoas próximas sua condição de soropositiva.

[...] minha mãe chega e fala [...] amamente seu filho menina! [...] eu não falei ainda que sou soropositiva. Minha irmã que sabe. Eu fico triste, mas fazer o quê? Quando minha mãe perguntou, eu disse para ela que o leite secou e eu não vou amamentar ele e eu não quero, ai ela disse que está muito triste [...] mas eu não tive coragem ainda de contar a minha mãe. (Mulher 2 SP HIV).

[...] o povo ficava perguntando por que eu não amamentava [...] eu ficava com vontade de chorar, porque eu não podia falar. Eu dizia que não tinham me falado nada. (Mulher 10 SP HIV).

Nas situações inventadas, as mulheres alegavam, especialmente, estar apresentando algum problema de saúde, conforme aparece nos discursos:

[...] quando as pessoas me perguntavam por que eu não estava amamentando, eu dizia por que eu estava com problema no pulmão. Eu negava, tinha vergonha de dizer [...] (Mulher 4 SP HIV).

Neste grupo de mulheres, as justificativas foram diversificadas, a saber: não quero, não posso, não tenho leite, meu leite é pouco, fraco, não serve, secou, meu leite está com problemas, estou tomando remédios, o bebê não aceita, estou com problema de saúde, com problemas no sangue, estou doente, com anemia, hepatite, infecção puerperal, não gosto de amamentar, o leite não foi produzido e os peitos podem cair.

\section{Discussão}

O estudo apresentou limitações referentes à restrição da localidade - uma vez que as representações expressas nos sentimentos são de mulheres soropositivas em tratamento no município de Salvador -, assim como aos aspectos metodológicos - por se valer da abordagem qualitativa e, desse modo, não ser possível a generalizações dos resultados. Estes, no entanto, apontaram para novos conhecimentos científicos que podem ser agregados ao planejamento da assistência e ao cuidado prestado por profissionais de enfermagem às mulheres soropositivas para HIV e HTLV que têm filhos recém-nascidos. Além disso, é fundamental conhecer os sentimentos dessas mães diante da vivência da não amamentação devido ao contágio do leite materno, com base nas representações sociais apreendidas do senso comum e dos seus sistemas de significações. Desse modo, os profissionais de enfermagem poderão pensar/agir e propor o cuidado congruente e individualizado, condizente com o que significa ser mulher, mãe, soropositiva e não poder amamentar o filho.

Os sentimentos de tristeza, medo, culpa, incerteza e raiva expressados pelas mães sobre a vivência da não amamentação contribuem para a construção e interpretação da realidade social. O entendimento deste cotidiano é possível com base na compreensão de construções mentais de pessoas que se originam na vida cotidiana e vivenciam um fenômeno/realidade comum a um conjunto social ${ }^{(8)}$. Neste estudo, as representações ajudam a entender como as mulheres sentem-se diante da impossibilidade de amamentar, uma vez que convivem com a soropositividade.

Os sentimentos expressos nas representações das mulheres sobre a não amamentação permitiram constatar-se que, mesmo conhecendo o 
seu estado sorológico, elas mantinham o sonho e o desejo de amamentar. No entanto, o não amamentar para manter a saúde do filho obrigou-as a sufocar tal desejo. Portanto, as mães que não amamentaram vivenciaram a maternidade negando o leite materno ao seu filho, o que, em algumas situações, pode ser delicado e constrangedor perante outras mulheres e a sociedade, além de ser penoso e causar sofrimento ${ }^{(9)}$. Isso pode significar a perda do sonho de colocar em prática suas habilidades e afetividades maternas simbolicamente representadas pelo ato de amamentar.

O rompimento do sonho de não poder amamentar ocasiona sofrimento psicológico, pois é como se a mãe negasse o alimento considerado como ideal e difundido na mídia como "O melhor remédio para a saúde do filho" ${ }^{(10)}$. Neste caso, destacando apenas o leite das mulheres que podem amamentar e esquecendo-se daquelas que não podem amamentar, como as SP HIV e SP HTLV.

As campanhas de incentivo a amamentação aponta o aleitamento materno como desejável e ideal para manutenção da saúde das crianças, atribuindo à mulher a responsabilidade de promovê-la ${ }^{(10)}$. Na sociedade, a maternidade tem sido valorizada e instituída como responsabilidade/dever da mulher, contribuindo para o imaginário da amamentação como processo sociocultural e histórico. A maternidade também tem-se fundamentado em características construídas socialmente que remetem à afetividade (sentimentos como ternura e carinho), favorecendo o vínculo mãe-filho ${ }^{(11)}$.

Tais representações da maternidade também são centradas numa visão produzida socialmente, ainda nos séculos XVIII e XIX, que está relacionada à construção social de que a condição biológica da mulher confere-lhe o desejo da maternidade. Tal pensamento desconsidera questões que envolvem as dimensões psicológicas, culturais, sociais e históricas ${ }^{(12)}$.

Como as representações sociais são elaboradas no âmbito das comunicações entre grupos, articulando elementos da relação do indivíduo com o mundo e com o grupo, elas repercutem sobre as interações sociais e as mudanças sociais, iniciadas com o conteúdo elaborado por uma pessoa que passa por transformações sociais, culturais, políticas e históricas ${ }^{(11)}$.

Os três sistemas indutores de representação difusão, propagação e propaganda -, analisados por Moscovici, correspondem à formação dos estereótipos e das condutas por meio da comunicação ${ }^{(12)}$. No que se refere à representação da amamentação como símbolo da maternidade, está atrelada ao sistema de difusão, uma vez que as informações não são dirigidas a um grupo, mas a uma pluralidade de grupos, e a mensagem sobre um objeto é organizada de maneira indiferenciada, ignorando as diferenciações sociais e não provocando mudanças de atitude $\mathrm{e}^{(13-14)}$. Logo, esquecem-se de que existes outras mulheres que não podem amamentar, simplesmente porque não desejam ou porque possuem contraindicação, como a soropositividade para o HIV e HTLV.

Pesquisas destacam que a abstinência da amamentação devido ao contágio do leite pelo HIV despertou nas mulheres, de um lado, a tristeza por não terem amamentado seus filhos e, de outro, a felicidade por não terem contaminado os filhos com os vírus ${ }^{(9-10,15-16)}$. Outros sentimentos, como sofrimento, frustração, medo e angústia também foram verbalizados pelas mulheres diante da não amamentação. Contudo, algumas mulheres entendem o não amamentar como algo normal, seja por experiências anteriores não muito agradáveis ou simplesmente porque isso significou um benefício para a criança, neste caso a não contaminação pelo vírus. Ademais, ter recebido ajuda para alimentar o filho minimiza a angústia, a incerteza e o medo quanto ao alimento a ser oferecido para a criança em substituição à amamentação.

Sendo assim, foi possível observar que, quando houve mudança no contexto de ativação da representação social do objeto, isto é, da contaminação do leite materno e não amamentação, a conduta diante dessa representação aconteceu de forma menos dolorida. Isto porque o estranho tornou-se familiar e o abstrato tornou-se concreto. O conceito transformou-se em 
uma imagem capaz de reproduzir visivelmente uma ideia ${ }^{(13)}$, a qual pode ser identificada com base em critérios culturais e normativos, esquematizados desde o núcleo figurativo, por meio da naturalização de um elemento abstrato materializado em elementos da realidade mediante classificação e nomeação ${ }^{(14)}$.

O não amamentar provocou alterações físico-orgânicas visíveis e sentidas no corpo feminino, especialmente as alterações mamárias, sentimentos de tristeza, sofrimento e dor. Houve relatos de dores, febre e frio, fazendo com que esse período fosse vivenciado pelas mulheres com dificuldades e sofrimento, demonstrando a falta de habilidade dos profissionais de saúde em lidar com essas questões.

Assim, ao ter suas mamas enfaixadas, as mulheres enfrentaram desordens emocionais que as afetaram em suas diferentes dimensões: física, psíquica, social e cultural. Elas expressaram vários sentimentos, que desencadeavam conflitos internos, oriundos de construções sociais sobre o ser mãe/mulher, como o constrangimento diante da visibilidade da não amamentação que o enfaixamento provoca diante de familiares e da sociedade, logo, o medo da possível descoberta de sua condição sorológica; os desconfortos e as dores em suas mamas decorrentes do enfaixamento; além da preocupação estética com o seu corpo, devido à relação dos seios com o ser mulher ${ }^{(5,9)}$. Muitas vezes, tais representações verificadas nesses sentimentos não são identificadas pelos profissionais, o que compromete o cuidado àquelas que convivem com a impossibilidade da amamentação.

Ao justificarem socialmente a não amamentação, as mulheres soropositivas sofrem duplamente - por não estarem amamentando e pela condenação da soropositividade. Ao sentirem medo do estigma e da discriminação social, escondem o seu estado sorológico, inclusive para a própria família. Além disso, há o constrangimento para uma mulher soropositiva, ao se sentir cobrada de forma explícita ou implícita pelos profissionais de saúde, familiares e amigos do porquê de tal comportamento, pois, na maioria dos casos, essas pessoas desconhecem a condição de soropositividade da mulher e levam em consideração o dever de amamentar. No entanto, a cobrança social coloca-as em situações constrangedoras, sem considerar aspectos como a dor do não amamentar e a punição social que carregam consigo. Por isso, criam desculpas socialmente aceitas para justificar a não $\operatorname{amamentação~}^{(5,17)}$.

Para tanto, as mulheres valeram-se das alegações relacionadas à condição materna (problema no pulmão, açúcar no sangue), com a baixa produção de leite (não tenho leite, leite pouco, leite secou) ou simplesmente porque não queriam amamentar, ou não sabiam a razão de terem sido proibidas de aleitar. Das alegações relacionadas ao recém-nascido, apenas foi citada a recusa ao peito. Assim, para não sofrerem tal constrangimento, as mulheres utilizaram-se de alegações do senso comum e que não são justificadas e aceitáveis cientificamente.

Para que o cuidado dos profissionais de saúde se estabeleça de forma eficiente, é necessário o desenvolvimento de habilidades para lidar com as mulheres que convivem com a condição da soropositivdade e com o recém-nascido, tendo como base as necessidades apresentadas e representadas socialmente por elas, de modo a garantir a preservação de questões pessoais delas, oferecendo-lhes, sobretudo, apoio e orientação nessa situação singular e difícil ${ }^{(9)}$.

Destarte, com vistas a garantir a prevenção da transmissão vertical, faz-se necessário o acompanhamento da mulher desde a assistência pré-concepcional, no intuito de conhecer a condição sorológica da futura mãe, assim como investir em campanhas educativas que atentem para os cuidados preventivos. Além disso, durante o pré-natal é fundamental o aconselhamento antes e pós-testagem, o qual requer a construção de confiança mútua ${ }^{(18)}$. Dessa forma, no puerpério, a lactente estará condicionada e sensibilizada da necessidade de não amamentar. Para tanto, a propaganda é uma forma de comunicação de um grupo que oferece uma visão clivada de mundo, cuja dinâmica encontra-se inscrita nas relações sociais conflituosas, salientando-as e acentuando as diferenças sociais ${ }^{(12,14,19)}$. 
Desse modo, "[...] devem ser criados ambientes apropriados para diminuir o estigma e a discriminação" ${ }^{(18 ; 753)}$ aos quais essas mulheres estão expostas, tendo como "[...] estratégia assistencial, o encontro vivido e dialogado, mediado pela escuta, empatia e intersubjetividade, se desenvolve a partir da compreensão do modo de ser do humano" ${ }^{(5 ; 82)}$.

Reconhece-se, dessa forma, que é necessário investir em novos princípios de racionalidade, possibilitando o acesso ao espaço das representações, dos significados, de novas possibilidades de interação interpessoais e de reconhecimento do mundo. Essa nova racionalidade exige que a aptidão profissional no campo da saúde passe a abranger a capacidade de observar e de ouvir, reelaborando conceitos, descrições e taxonomias com base nos discursos e nos gestos ${ }^{(20)}$.

Como a representação social é uma construção interativa, objetivada e ancorada em situações vivenciadas no cotidiano, ela origina-se com indívíduos pertencentes a um grupo, cuja natureza é relacional, apoiada no campo psico-cognitivo de cada um. Desenvolvida e compartilhada dentro desses grupos sociais, as representações sociais ganham novos significados e conhecimentos, transformando-se ao longo dos tempos $^{(21)}$.

\section{Conclusão}

A não amamentação, para o grupo investigado, é representada como um ato conflituoso entre o desejo de amamentar, fomentado pelas construções sociais da maternidade, e o de manter o seu filho saudável, livre da transmissão vertical pelo HIV ou HTLV. Os sentimentos de tristeza, culpa, raiva e frustração decorrentes da decisão de não amamentar geram sofrimentos que afligem o corpo e a mente das mulheres. Ao ancorarem e objetivarem a não amamentação como algo árduo e difícil de ser concebido em seus sistemas cognitivos, as mulheres ressignificam as representações da não amamentação por meio de sentimentos conflitantes para o enfrentamento da soropositividade.
Os sentimentos das mulheres investigadas evidenciam a necessidade de reflexão sobre a prática da amamentação como uma ação de proteção e de amor recomendada pelos profissionais de saúde, visto que nem todas as mulheres podem adotar essa prática. Para estas, a não amamentação pode constituir-se numa ação de proteção e de amor que exige superação e causa sofrimento. Na prática profissional, enfermeiras têm a possibilidade de intervir na situação da não amamentação incentivando/apoiando a mulher na sua decisão.

Conclui-se que os sentimentos das entrevistadas acerca da não amamentação estão permeados por conflitos oriundos de padrões socioculturalmente estabelecidos com relação à amamentação. Na prática profissional, enfermeiras têm a possibilidade de intervir na situação da não amamentação, apoiando a mulher na sua decisão.

\section{Colaborações:}

1. concepção, projeto, análise e interpretação dos dados: Marizete Argolo Teixeira e Mirian Santos Paiva;

2. redação do artigo e revisão crítica relevante do conteúdo intelectual: Marizete Argolo Teixeira, Mirian Santos Paiva, Pablo Luiz Santos Couto, Jeane Freitas Oliveira e Rafael Moura Coelho Pecly Wolter;

3. aprovação final da versão a ser publicada: Marizete Argolo Teixeira, Mirian Santos Paiva, Pablo Luiz Santos Couto, Jeane Freitas Oliveira e Rafael Moura Coelho Pecly Wolter.

\section{Referências}

1. Padoin SMM, Terra MG, Souza IEO. Mundo da vida mulher que tem HIV/AIDS no cotidiano da (im)possibilidade de amamentar. Esc Anna Nery. 2011;15(1):13-21.

2. Brasil. Ministério da Saúde. Secretaria de Atenção à Saúde. Departamento de Ações Programáticas Estratégicas. Gestação de alto risco: manual técnico. Brasília; 2012. 
3. Villaverde JA, Romaní FR, Torres SM, Zunt JR. Transmisión vertical de HTLV-1 em el Perú. Rev Peru Med Exp Salud Publica. 2011;28(1):101-8.

4. Frigo J, Zocche DA, Silveira S, Marin SM, Jesus M, Rodriguez $\mathrm{H}$, et al. As percepções das mulheres portadoras de HIV/AIDS perante a impossibilidade da amamentação. J Res: Fundam care. online. 2014 [cited 2017 Feb 10];6(2):627-36. Available from: http://www.redalyc.org/articulo. oa?id $=505750622018$

5. Padoin SMM, Souza IEO, Paula CC. Cotidianidade da mulher que tem HIV/AIDS: modo de ser diante da (im)possibilidade de amamentar. Rev Gaúcha Enferm. 2010;31(1):77-83.

6. Martins FM, Rezende NPM, Magalhães MHCG, Ortega KL. Conhecendo o HTLV e suas implicações no atendimento odontológico. RGO - Rev Gaúcha Odontol. 2011;59(2):293-7.

7. Champs APS, Passos VMA, Barreto SM, Vaz LS, Ribas JGR. Mielopatia associada ao HTLV-1: análise clínico-epidemiológica em uma série de casos de 10 anos. Rev Soc Bras Med Trop. 2010;43(6):668-72.

8. Gomes AMT, Barbosa BFS, Oliveira DC, Wolter RMCP, Silva MVG. As representações sociais de enfermeiros sobre a criança soropositiva para HIV: interface com o cuidado. Rev Enferm UERJ. 2011;19(1):14-9.

9. Costa MAS, Vieira BDG, Alves VH, Rodrigo DP, Leão DCMR, Pereira AV. Cuidado de enfermagem às puérperas soropositivas para o HIV diante da impossibilidade de amamentação natural. J Res: Fundam Care. online. 2015 [cited 2016 Nov 20];7(2):2310-22. Available from: http://www. redalyc.org/articulo.oa?id=505750946011

10. Machado MMT, Braga MQC, Galvão MTG. Problemas com a mama puerperal revelados por mães soropositivas. Rev Esc Enferm USP. 2010;44(1):120-5.

11. Moreira MA, Nascimento ER, Paiva MS. Representações sociais de mulheres de três gerações sobre práticas de amamentação. Texto Contexto Enferm. 2013;22(2):432-41.
12. Patias ND, Buaes CS. "Tem que ser uma escolha da mulher"! Representações de maternidade em mulheres não-mães por opção. Psicol Sociedade. 2012;24(2):300-6.

13. Costa FG, Coutinho MPL, Santa IO. Insuficiência renal crônica: representações sociais de pacientes com e sem depressão. Psico-USF. 2014;19(3):387-98.

14. Costa FG, Coutinho MPL. Hemodiálise e depressão: representação social dos pacientes. Psicol Estudo. 2014;19(4):657-67.

15. Gonçalves VF, Teixeira DQ, Oliveira PF, Sousa TH. Mulheres HIV positivas diante da maternidade. Rev Bras Promoc Saúde. 2013;26(2):281-9.

16. Vasconcelos SG, Galvão MTG, Paiva SS, Almeida PC, Pagliuca LMF. Comunicação mãe-filho durante amamentação natural e artificial na era Aids. Rev Rene. 2010;11(4):103-9.

17. Santos SFF, Bispo Jr JP. Desejo de maternidade entre mulheres com HIV/AIDS. Rev baiana saúde pública. 2010;34(2):299-310.

18. Brasil RFG, Moreira MMC, Teles LMR, Damasceno AKC, Moura ERF. Grau de conhecimento, atitudes e práticas de puérperas sobre a infecção por HIV e sua prevenção. Acta paul enferm. 2014;27(2):133-7.

19. Gomes GC, Pintanel AC, Strasburg AC, Xavier DM. Face singular do cuidado familiar à criança portadora do vírus HIV/AIDS. Acta Paul Enferm. 2012;25(5):749-54.

20. Carinhanha JI, Penna LHG, Oliveira DC. Representações sociais sobre famílias em situação de vulnerabilidade: uma revisão da literatura. Rev enferm UERJ. 2014;22(4):565-7.

21. Oswald SES. The potential of Social Representations Theory (SRT) for gender equitable research. Acta Colombiana Psicol. 2013;16(2):63-70.

Recebido: 1 de abril de 2017 Aprovado: 17 de julho de 2017 Publicado: 26 de outubro de 2017 